\title{
The Need for Comprehensive Counselling Services in Institutes of Higher Education in India
}

\author{
Dr. S. T. Janetius 1 , Dr. Mini. T. $\mathrm{C}_{2}$
}

\begin{abstract}
:
Adolescence is a period of quarter-life transition and college becomes the courtyard for this development. Adolescents, especially college students come to limelight for involving in various antisocial activities, campus violence, ragging incidents, eve-teasing, suicides, and multifarious relationships much more than productive academic pursuits. This has become a great concern for higher education institutions in India. Various government and nongovernment bodies have raised alarm over these untoward adolescent and campus related issues and, highly recommend counselling services in the campuses. However, no comprehensive counselling or guidance program has been drafted by the governing bodies to assist the students or manage adolescences for betterment. Although India has the ancient gurukula tradition which paved the way for a holistic and integral development through education, counselling and wellbeing services have not taken deep roots today in the educational system. This empirical study proposes a comprehensive counselling service for the institutes of higher education by studying the major problems of college students in Tamil Nadu.
\end{abstract}

Keywords: Counselling, Higher Education

\section{INTRODUCTION:}

Professional counselling is essentially a process of therapeutic interpersonal interaction, dialogue and communication based on the conviction that each human being has an innate ability to judge and implement the decisions taken concerning life. Therapeutic dialogue has been part of various cultures and religions. In the Bible, a dialogue between Jesus and the Samaritan woman has been identified as therapeutic discourse; Bhagavad Gita has one of the oldest recorded therapeutic dialogues between Krishna and Arjuna in the gurushetra which resembles the therapeutic counselling of today. However, professional counselling which focuses on the comprehensive development of a person has yet become popular in Indian scenario.

\footnotetext{
${ }^{1}$ Director \& Head, Department of Psychology, Sree Saraswathi Thyagaraja College, Pollachi Coimbatore, Tamil Nadu

${ }^{2} \mathrm{CAO}$, Cheran Group of Institutions, Coimbatore

(C) 2015, S Janetius, T Mini; licensee IJIP. This is an Open Access Research distributed under the terms of the Creative Commons Attribution License (http://creativecommons.org/licenses/by/2.0), which permits unrestricted use, distribution, and reproduction in any Medium, provided the original work is properly cited.
} 


\section{The Need for Comprehensive Counselling Services in Institutes of Higher Education in India}

Guidance and Counselling is a uniquely American educational innovation, started by Frank Parsons in the early 1900s as vocational guidance. It has developed today into one of the exceptionally essential and integrated services that focus on the complete development of students. In the developed countries it is organized as a series of services involving not only counsellors but also the faculty, administrators, staff and other personnel in the organization. It is designed to maximize learning, stimulate clarity in career choices, and provide timely response to personal and social concerns that inhibit growth and development.

As we learn from the well-organized school and college counselling services of the developed countries, using counsellors to directly support the college's academic mission gains currency today. The Association for School Counsellors in America identifies 3 primary roles: prevention and intervention programs, consultation services and coordination (Gibson \& Mitchell, 2003). To achieve maximum program effectiveness, the American School Counsellor Association recommends a counsellor-to-student ratio of 1:250 (Kaplan \& Owings, 2010).

The importance of counselling services in the schools and colleges particularly with reference to vocational and career guidance has been emphasised in India since late 1930's when the Acharya Narendra Dev Committee emphasized the need of it (Bhatnagar \& Gupta, 1999). However, it did not take roots in the Indian educational system as seen in the Western or Eastern developed countries. Although serious calls for mental health assistance have been raised by various government bodies, they remain inattentive. A study done in 26 colleges all over India by Arulmani (2004) identifies that only six of the lecturers who were in charge of guidance and counselling had a background in behavioural sciences and only three of them were trained in counselling. Similar findings have also been reported by a few other earlier studies (Bhatnagar \& Gupta, 1999).

The traditional indigenous guru-shishya parampara which emphasises the relationship between the teacher and students, carried out with the sense of responsibility of forming and shaping the young in the gurukula has been eroded and lost in the various hegemony of kingdoms, religious invasions and colonization. Today's educational system doesn't bear even the imprints of gurukula. Schools and colleges have become more and more commercialised than development oriented (Sahni, 2005). The guidance and the related counselling services, supposedly the powerhouse of wellbeing for students, are apathetically neglected (Shetty, 1996). In the Indian educational scenario counselling is often understood as academic advising or vocational guidance. The very concept of student wellbeing and mental health counselling in the educational sector remains in its embryonic stage, which in turn accounts for the increased number of college students neglecting academic pursuits with an inaccurate and uncertain 


\section{The Need for Comprehensive Counselling Services in Institutes of Higher Education in India}

academic goals enter into a variety of workplaces which affects various segments of the society (Janetius, Mini \& Chellathurai, 2011).

An emerging major concern and mental health issue among college students is anxiety and depression due to various causes (Ganesh, 2008). Added to that, ragging today has become a notorious practice and offence in the colleges and universities in the camouflage of welcoming and introducing the fresher to the college portals. It has taken such a heartless shape that the central government of India and UGC have repeatedly warned serious action against those who involve in such ruthless and barbaric acts. It is widespread to see students who are tormented and teased take to harm themselves and others (Chopra, 2009; Daily Thanthi, 2008). Besides ragging, use of alcohol, peer pressure for gangs in the college premises have become the dominant culture today (Devraj, 2009; Ram \& Sharma, 2005). The increasing number and the effects of broken families and the absence of parental supervision and unethical parental lifestyle have contributed to various campus students misbehaviours (Raj, 2006). Added to that, the lack of respect for authority and poor family interaction with the teachers and authorities lead to the growing trend of violence related campus incidents (Chopra, 2009).

The National Population Policy (2000) has recognised adolescents as an underserved susceptible group that needs to be served by providing assistance and guidance. Universities and colleges are the platforms where adolescents enter adult life. One can rightly say that quarter-life transition takes place in the courtyards of colleges. This quarter-life transition places the adolescents in a critical period of confusion and excitement (Shilpa, 2012). This blend of confusion and excitement in turn influences the overall interpersonal issues and bonds and other life-situations in the college. Thus, this turbulent period, if not guided and supervised appropriately, may result in adversity and misfortunes. Also, this is the period in which the glimpses of their career concerns and the related decision making process emerge which in turn divert them from serving different sections of the society (Mini, 2011). As Erikson points out, this is the period in which young people establish their indelible personal as well as social identity (Erikson, 1968 \& 1970).

\section{AIM OF THE STUDY:}

In view of the current scenario of students in institutes of higher education, this research is focused on identifying the need for an establishment of a comprehensive counselling service. The specific objectives of the study are:

- To identify the major concerns of college students that need counselling assistance

- To identify the various constrains in offering quality counselling services 


\section{The Need for Comprehensive Counselling Services in Institutes of Higher Education in India}

- To prepare a comprehensive counselling program in the Indian higher education scenario

\section{METHODOLOGY:}

This qualitative exploratory study was conducted in Tamil Nadu. A research investigator was appointed to the required collect data for the period of nine months. Using lottery method 96 colleges were selected (3 colleges from 32 administrative districts) and 5\% students representation from each college was used to gather data. A survey questionnaire was prepared to collect data from students, who were willing to participate. Data from 4824 students were collected, of which 178 were rejected due to incomplete answers and 4646 were chosen for the study. Besides identifying themes and categories from the data collected as per the qualitative analysis, percentage and rank order methods were also used for data analysis.

\section{ETHICAL CONSIDERATIONS:}

The code of ethics as adapted by the declaration of Helsnk's1987 are applied to this research. Therefore, respondents will be protected from mental and physical harms. The investigator was advised and instructed to keep the best interests of the respondents as the foremost concern while collecting data. The respondents were informed that their responses would be kept confidential, and necessary steps were taken for keeping confidentiality. The respondents were also informed that they have the right to know the findings of the study.

\section{RESULTS AND DISCUSSION}

The following table shows some of the basic information about the subjects being studied.

Table 1: Background information about the subjects in percentage $(n=4646)$

\begin{tabular}{|c|c|c|c|c|c|c|}
\hline Male & Female & $\begin{array}{c}\text { Colleges in } \\
\text { Rural } \\
\text { Setting }\end{array}$ & $\begin{array}{c}\text { Colleges in } \\
\text { Urban } \\
\text { Setting }\end{array}$ & $\begin{array}{c}\text { UG } \\
\text { Students }\end{array}$ & $\begin{array}{c}\text { PG } \\
\text { Students }\end{array}$ & Diploma \\
\hline 47.84 & 52.16 & 56.25 & 43.75 & 81.08 & 15.84 & 3.08 \\
\hline
\end{tabular}

\section{Major problems of college students}

Nearly 33.02 percentage of the students being studied reported that they were disturbed by one or another problem during the last six months that needed some assistance from others. The significant issues behind this disturbance were identified as: friends (22.75\%), economic related issues (21.65\%), family problems $(19.42 \%)$ and love affairs $(17.75 \%)$. This shows that a great number of students are having some major 
issues that obstruct their focus on studies. The following table presents the top 10 problems of students in percentage reported by them.

Table 2: Top ten problems of the students that need counselling assistance $(n=4646)$

\begin{tabular}{|l|l|c|}
\hline No & Problems & Percentage \\
\hline 1. & Insomnia & 36.11 \\
\hline 2. & Feeling of loss & 36.09 \\
\hline 3. & Inferior feeling & 33.03 \\
\hline 4. & Lack of self-confidence & 28.99 \\
\hline 5. & Ill-treatment and harassment by teachers & 26.75 \\
\hline 6. & Unknown fear in the mind & 21.48 \\
\hline 7. & Hurt in the inner-self & 19.78 \\
\hline 8. & Bleak future & 18.20 \\
\hline 9. & Harassment by classmates and other students & 17.97 \\
\hline 10. & Disturbing thoughts & 16.35 \\
\hline
\end{tabular}

Adolescent period which could be seen broadly up to 22 years of age is a distinctive period in human development. It is a period of major changes in the development of brain, emotions, cognition, social behaviour, and interpersonal relationships (Rosso, Young, Femia \& Yurgelun-Todd, 2004). Almost all the major problems identified in the study reflect the overall developmental dilemma and concern of adolescent growth.

The problem that ranks first among college students is insomnia. Nearly 36 percent report this as one of the problems they face as adolescent college students. The major reasons identified by the students are: thoughts about future (36.82\%) and, love affairs (26.87). Global studies also identify poor and lack of sleep as a major problem among adolescents and DSM-IV has some diagnostic criteria for adolescent insomnia (Dohnt, et al, 2012). Lack of sleep goes negatively on cognitive functions and other performances and is often associated with poor emotional and physical health problems (Roberts et al, 2000). Regarding the major problems of the students in the wake of infamous ragging incidents all over India, the study identifies more students suffer from ill-treatment from teachers $(26.75 \%)$ than students who suffer from peers $(17.97 \%)$.

The various problems faced by the college students lead to three critical situations in which they feel that there is no one to talk (41.19\%), yearning for good friends (51.55\%) and suicidal tendency (15.45\%). 
The Need for Comprehensive Counselling Services in Institutes of Higher Education in India

Table 3: The current mental health situation of the students

\begin{tabular}{|c|l|c|l|c|}
\hline S No & \multicolumn{1}{|c|}{ Problem } & Percentage & \multicolumn{2}{|l|}{ Reason for the problem } \\
\hline \multirow{2}{*}{1.} & Nobody to talk & 41.19 & \multicolumn{2}{|l|}{} \\
\hline 2. & Yearning for good friends & 51.55 & \multicolumn{2}{l|}{} \\
\hline 3. & Attempted Suicide & 12.20 & & 39.97 \\
\hline $4 .$. & Suicidal tendency & 15.45 & Love affair & 18.25 \\
\cline { 3 - 5 } & & & Family problems & 16.85 \\
\cline { 4 - 5 } & & & $\begin{array}{l}\text { Thinking about } \\
\text { future }\end{array}$ & 25.53 \\
\cline { 4 - 5 } & & & Other reasons & \\
\hline
\end{tabular}

The results of the study show a high percentage of suicide attempts (12.20\%) and suicidal tendency (15.45\%) among college students. The study conducted by Sharma (2008) among adolescent students in south Delhi reports 15.8 percent have thought of attempting suicide, while 5.1 percent had actually attempted suicide. The current study results in Tamil Nadu shows a high rate of suicide attempts compared to their counter parts in Delhi. Love-affairs remain at the top of all reasons for suicide among the study subjects. The various behavioural deviances among students are listed in the table below.

Table 4: Behavioural deviance

\begin{tabular}{|l|l|c|}
\hline & & Percentage \\
\hline 1. & Involvement in violent activities & 23.05 \\
\hline 2. & Antisocial activities & 14.50 \\
\hline 3. & Smoking & 11.75 \\
\hline 4. & Pan, Kutka & 7.99 \\
\hline 5. & Alcohol use & 14.15 \\
\hline 6. & Narcotic Drugs & 6.57 \\
\hline
\end{tabular}

\section{Constrains in offering quality counselling services}

The study results show that in 96 percent of the colleges counselling services are not available and very few colleges have functional counselling assistance. In some colleges counselling services are integrated with some departments or entrusted with one or another faculty. Therefore, some major constraints in offering quality counselling services come from two ways: 1) No exclusive counselling department to offer services 2) No qualified fulltime counsellors to understand the dynamics of adolescents to offer assistance. 


\section{Comprehensive counselling program in the Indian higher education scenario}

College students are in their latter adolescent period and being forced to respond to many interpersonal, societal problems. These affect their academic endeavours indicated by high rate of unfocused academic pursuits, depression and suicidal tendencies, substance abuse, premarital sex and abortion, tensions with peers, parents, teachers, engaging in gangs, and other violent behaviours. An ideal college counselling program therefore should offer both prevention and intervention services directly and indirectly that intervene in a significant way to enhance the overall academic performance of the students. These services are part of providing quality education for personal growth and sustainable development.

\section{General guidelines for program development and management}

a) Structures - qualified full-time counsellors, separate counselling office, rooms with spacious private rooms to conduct counselling sessions.

b) Vision, mission - a well defined vision and mission statement that outline the general orientation to the counselling program.

c) Needs Assessment - knowledge about the needs of the students in the campus by way of regular needs assessment survey and analysis.

d) Coordination with other offices in the campus - regular contact with teachers and administrative office to update statistics about the demographic characteristics of the students like, gender, socioeconomic status, dropout rates, academic attitude, achievement level, and classroom climate.

e) Customary programs - besides individual and group counselling sessions, organize on a regular basis various prevention and intervention services, faculty development programs, renewal courses for students, faculty and administrators.

f) Consultation and collaboration - regular consultation with teachers, student deans, administrators and parents for organising various programs for student wellbeing.

g) Evaluation - periodical evaluation is needed to revise, update and effectively implement various activities. Evaluation involves planning and implementation of various activities, assessing practice and the outcome of services offered by the counselling program. 


\section{Proposed Program Components}

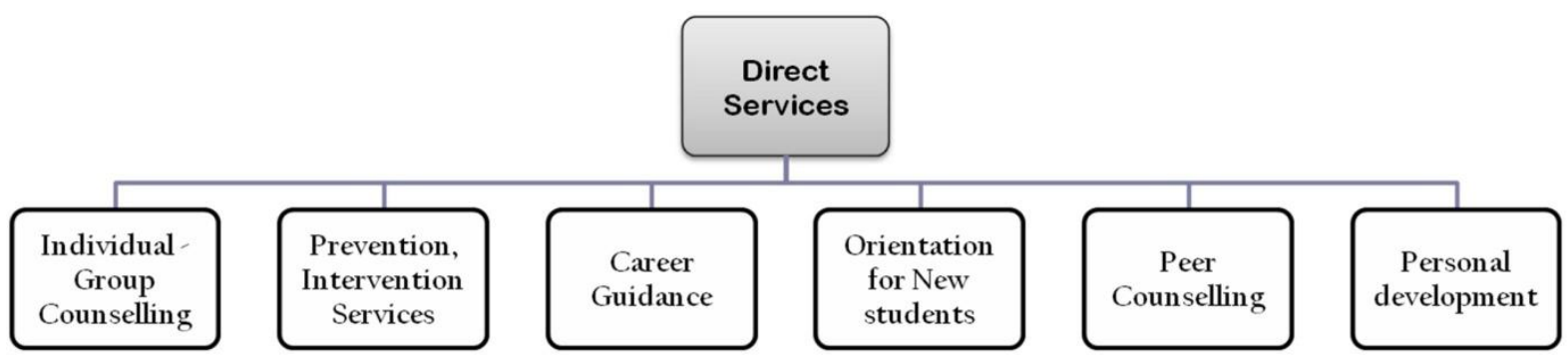

Figure 1: Showing direct services

Individual \& group counselling: Individual counselling is the major activity of the counselling centre and it is vital in helping the students. In individual counselling gives privacy and confidentiality. Group therapy allows a counsellor to provide assistance to more students than would be possible otherwise. Group therapy allows students to hear and see how others deal with their problems and can receive vital support and encouragement from other students.

Prevention/intervention services: Prevention is an effort that seeks to avoid the occurrence of something undesirable where as intervention is or remedial is overcoming undesirable developments. With this idea counselling centre can identify various preventions and intervention activities depending upon the various needs of the college. It can be of great help in helping students from smoking, drug abuse and other deviances.

Career guidance: Psychologists identify aptitude and interest as the key to success in any vocation and profession. A good number of students enter into jobs that has nothing to do with their academic background. The career guidance services can help the students in overcoming many of their future worries and decision makings regarding their career choice and profession.

Orientation for new students: When young people enter into college, adjustment to the new environment becomes a major concern. New study habits, relationships, lifestyle... etc are the major contributing factors of anxiety, worry and depression. Proper guidance can be of great help for fresh students.

Peer counselling: Peer counsellors are student volunteers, who receive orientation and available in the classroom to help students in their problems. They are expected to assist the counselling centre by identifying problem students and referring them for counselling services. Peer counsellors expand the counselling centre's services to the classrooms and become a bridge between counselling centre professionals and the students. 
Personal development: The developmental dilemmas of adolescents could be tackled by various programs organized regularly that will help them to create their identity and other human development concerns so that the adolescents can pass the quarter-life transition smoothly.

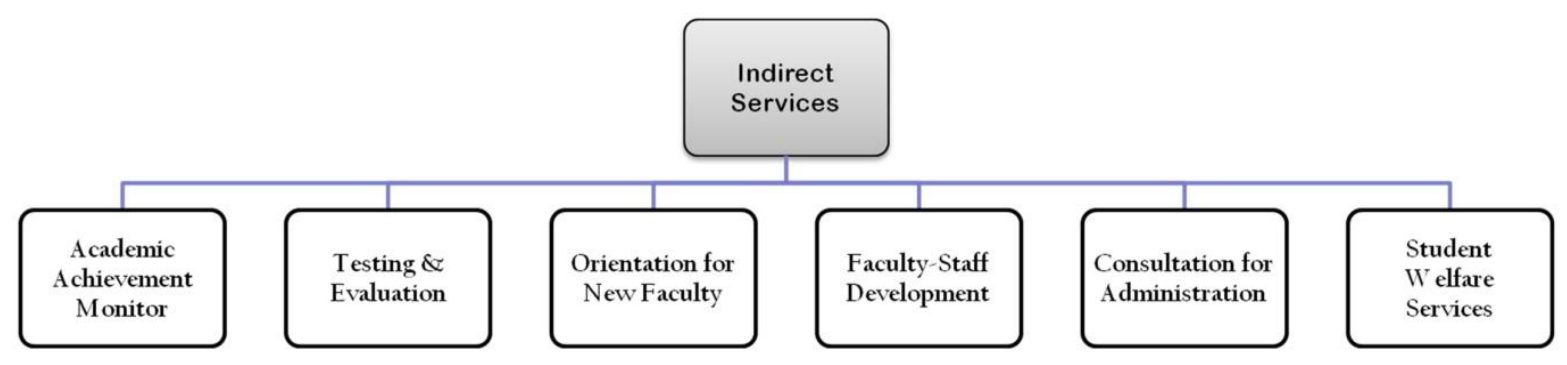

Figure 2: Showing indirect services

One of the major indirect service need to be offered is consultation that is, helping staff, teacher and administrators to become more effective in helping the students to transform as mature individuals. This also may involve parental counselling. Mainly, the teachers undergo enormous pressures related to classroom stress, compensation, and relationships with school officials. Counsellors can serve as a collaborator, colleague, and ally for teachers. Counsellors can use solution-oriented consultation to help teachers not only function better but also to improve attitude and reduce stress. Yet another role of counsellor would be coordination. Counsellor's intervention by means of various indirect services places them as a liaison between students and various other departments.

\section{CONCLUSION}

The study conducted in Tamil Nadu identifies the various mental health problems faced by students in the institutes of higher education. The college students who are in a critical transition period of moving from adolescence to adulthood face a lot of adjustment issues, academic problems, personal development concerns, interpersonal conflicts which are part and parcel of adolescent's normal growth and development. The current educational setting fails to meet these demanding development needs of the college students which in turn lead to various problem behaviours and mental health concerns. A comprehensive counselling program can help the adolescents in the critical period of confusion and excitement and make them more productive.

\section{REFERENCES}

1. Arulmani, G., \& Nag Arulmani, S. (2004). Career counselling: A handbook. New Delhi: Tata McGraw-Hill

2. Bhatnagar, A. \& Gupta, N. (1999). Guidance and counselling: A theoretical perspective (Volume 1). New Delhi: Vikas Publishing House 
3. Chopra, M. (2009). Ragging In Educational Institutes: A Human Rights Perspective, Retrieved on 15 April 2009 from World Wide Web Legal Service India.com

4. DailyThanthi, (2008). Adolescents and depression (Tamil Newspaper) November 28, 2008

5. Devaraj, R. (2009) Rights-India: Shades of Abu Ghraib in College Ragging Rituals, Global Issues, Inter Press Service, June 16, 2009

6. Dohnt, H., Gradisar,M., Short, M., (2012) . Insomnia and its symptoms in adolescents: comparing DSM-IV and ICSD-II diagnostic criteria. Journal of Clinical Sleep Medicine, 2012, 8(3):295-299

7. Erikson, E. (1968). Identity: Youth in crisis, New York: Norton

8. Erikson, E. (1970). Reflections on the dissent of contemporary youth, International Journal of Psychoanalysis, 51, 11-22

9. Ganesh, N. (2008). Student undergoes brutal ragging in TN college, Rediff News, October 16,2008

10. Gibson, R. \& Mitchell, M. (2003). Introduction to Counselling \& Guidance (6 ${ }^{\text {th }}$ ed.). New Delhi: Prentice Hall

11. Janetius S.T. \& Bekele. W. (2007). Evaluation of Counselling Services in the University of Gondar and a Conceptual model of counselling program, University of Gondar Compilation of Research paper presentations, University of Gondar, Ethiopia

12. Janetius, S. T., Mini, T.C., Chellathurai, J. (2011). School-based career development and the related parental counselling in India, Paper presented in the National Seminar on Changing Demands and Challenges for School Social Work, PSG College of Arts and Science, Coimbatore

13. Kaplan. L. \& Owings. W. (2010). American Education: Building a Common Foundation, KY: Cengage Learning

14. Mini, T.C. (2011). Linking Education with Employment: A Study on College Placement Cells, MISBAH Research Journal, Vol. 4, 2011

15. National Population Policy (2000). Department of Health and Family Welfare, Ministry of Health and Family Welfare, Government of India

16. Raj. M., (2006). Emotional landmines, The Hindu, March 19, 2006

17. Roberts RE, Roberts CR, Chen IG. (2000). Ethnocultural differences in sleep complaints among adolescents. Journal of Nervous and Mental Disease. 188: 222-229

18. Rosso, I. M., Young, A. D., Femia L. A., \& Yurgelun-Todd, D. A. (2004). Cognitive and emotional components of frontal lobe functioning in childhood and adolescence. Annals of the New York Academy of Sciences, 1021, 355-362.

19. Sahni, A. (2005). Health of educational systems in India, Health Administrator, Vol: XVII,1: pp. 4-11

20. Sharma,R., Grover,V.L., Chaturvedi, S. (2008). Suicidal behavior amongst adolescent students in south Delhi, Indian Journal of Psychiatry, Vol : 50: pp. 30-33

21. Sheety, H., (1996). Schools are neglecting counselling, Indian Express, June 28, 1996

22. Shilpa, S.T. (2012). Adolescent identity creation and grandparents - an autoethnography. In Janetius, et al (Ed.), Human rights abuse on elderly people. Delhi: Discovery Publishing House Pvt. Ltd. 